\title{
Overwhelming pneumococcal bacteraemia in systemic lupus erythematosus*
}

\author{
DAVID PETROS AND STERLING WEST
}

From the Department of Medicine, Division of Rheumatology, Fitzsimons Army Medical Center, Aurora, Colorado, USA

SUMMARY An 18 year old woman presented with fulminant pneumococcal bacteraemia and subsequently died with multisystem organ failure. A search for diseases predisposing to overwhelming encapsulated bacterial infections was negative except for previously undiagnosed systemic lupus erythematosus (SLE). This case emphasises the severity of immune system dysfunction in some patients with SLE, regardless of immunosuppressive treatment. The possible relation between Fc receptor dysfunction and pneumococcal bacteraemia in SLE is discussed.

Key words: septicaemia, infection susceptibility, splenic dysfunction.

Infection occurs at an increased rate in patients with systemic lupus erythematosus (SLE) and is a principal cause of death. ${ }^{12}$ This increased infection rate has previously been attributed to the increased use of immunosuppressive agents. ${ }^{3}$ Regardless of immunosuppressive treatment, however, there appears to be an increased risk of infection intrinsic to SLE, ${ }^{4}$ possibly secondary to defects in the immune surveillance system.

We present a young, previously healthy patient, who died of overwhelming pneumococcal bacteraemia as the initial presentation of SLE.

\section{Case report}

An 18 year old black woman was admitted to Fitzsimons army medical centre in respiratory failure. She was in excellent health until two weeks before admission. During these two weeks she complained of malaise, intermittent lower extremity arthritis, and chest pain compatible with pericardi-

Accepted for publication 16 July 1988.

Correspondence to Dr Sterling G West, Rheumatology Service, Department of Medicine, Fitzsimons Army Medical Center, Aurora, CO 80045-6000, USA.

${ }^{*}$ The opinions and assertions contained herein are the private views of the authors and are not to be construed as official or reflecting the views of the department of the army or Department of Defence. tis. In the 24 hours preceding admission the patient experienced rigors, high fever, and rapidly progressive respiratory distress.

Past medical and surgical histories were unremarkable. Her mother had died of overwhelming bacterial infection while receiving immunosuppressive drugs for SLE several years earlier.

On examination the patient was in severe respiratory distress. Her pulse was 150 beats a minute, blood pressure $105 / 70 \mathrm{mmHg}$, temperature $39.5^{\circ} \mathrm{C}$, and respirations shallow and laboured at 40 breaths a minute. Auscultation of the chest showed diffuse crackles in both lung fields and an intermittent pericardial rub. The left knee was warm and tender with a demonstrable effusion. The remainder of the examination was unremarkable.

Laboratory investigation showed a packed cell volume of 0.333 and a white cell count of $9.5 \times 10^{9}$ cells $/ 1$ with $35 \%$ neutrophils and $47 \%$ band forms. Intracellular cocci were seen on a peripheral blood smear. An arterial blood sample drawn while the patient was breathing room air showed a partial pressure of oxygen $\left(\mathrm{PaO}_{2}\right)$ of $5.2 \mathrm{kPa}$, a partial pressure of carbon dioxide $\left(\mathrm{PaCO}_{2}\right)$ of $5.2 \mathrm{kPa}$, and $\mathrm{pH} 7 \cdot 22$. The chest roentgenograph showed bilateral lobar infiltrates, cardiomegaly, and a small pleural effusion. An echocardiogram confirmed a small pericardial effusion without evidence of cardiac 
compromise. A left knee arthrocentesis showed $1 \cdot 18 \times 10^{9}$ cells $/ 1,100 \%$ lymphocytes, with negative Gram stain and culture. Sheets of polymorphonuclear cells and abundant Gram positive diplococci were seen on Gram stains of sputum.

On admission to the medical intensive care unit the patient required ventilatory support. Treatment with penicillin and cefotaxime was initiated for presumed bacteraemia. Severe lactic acidosis and recurrent bouts of hypotension necessitated continuous intravenous infusions of sodium bicarbonate and dopamine respectively. Her course was complicated by the development of clinical and laboratory evidence for disseminated intravascular coagulation. By the second hospital day there was progressive renal, cardiac, hepatic, and respiratory failure. Blood and sputum cultures were positive for Streptococcus pneumoniae. Despite aggressive medical management the patient's condition continued to deteriorate, and she died on the third hospital day.

While in hospital the patient was evaluated for diseases predisposing to overwhelming pneumococcal bacteraemia. A haemoglobin electrophoresis, serum protein electrophoresis, and immunoglobulins measured quantitatively were normal. At necropsy bilateral pneumonia and serosal haemorrhage consistent with disseminated intravascular coagulation were noted. The spleen was normal, except for minimal germinal centre atrophy and mild periarterial fibrosis.

Owing to the patient's family history and suggestive symptoms during the two weeks preceding admission, a diagnosis of SLE was considered. An antinuclear antibody determination was positive at a titre of $\geqslant 1 / 256$ in a speckled pattern. Analysis for specific antibodies showed a positive anti-SSA, positive anti-Sm at a titre of $\geqslant 1 / 128$ by counterimmunoelectrophoresis, and raised anti-doublestranded DNA antibody of $29 \%$ binding by Millipore filter assay (normal $<10 \%$ ). The positive antiSm antibody and raised DNA binding coupled with the clinical evidence of arthritis and serositis supported a diagnosis of SLE. Other studies showed a C3 of $120 \mathrm{mg} / 1$ (normal 830-1770), C4 of $20 \mathrm{mg} / 1$ (normal 150-450), $\mathrm{CH}_{50}$ of 8 units (normal 32-128), and circulating immune complexes raised at $64 \%$ (normal $0-13 \%$ ) by the C1q assay. Complement levels of a twin sister were normal, ruling out a congenital complement deficiency.

\section{Discussion}

Our patient's course of fulminant pneumococcal bacteraemia, disseminated intravascular coagulation, and multisystem organ failure is identical with the syndrome of infection after splenectomy pre- viously reported. ${ }^{\circ} \mathrm{A}$ search for other diseases? associated with this syndrome, including thalas saemia, sickle cell disease, immunoglobulin de $\stackrel{乛 \text { ? }}{乛}$ ficiency, congenital complement deficiency, an splenic abnormalities, was negative. This is the firse reported case of overwhelming pneumococcal bac $\frac{\text { ? }}{7}$ teraemia occurring as the presenting manifestation of SLE. The absence of immunosuppressive treat ment highlights the intrinsic risk of immune systemdysfunction in some patients with SLE.

The immune system abnormality predisposing this. patient to develop overwhelming pneumococcaR sepsis is probably due to a defect in bacteriagू clearance by the patient's reticuloendothelial sys $\Rightarrow$ tem. Previous reports have suggested an increased risk of infection with encapsulated bacteria, es pecially salmonella and the pneumococcus, in patients with SLE. ${ }^{78}$ To be cleared from the blood stream encapsulated organisms require opsonisation with specific immunoglobulin and complement facilitating attachment to splenic macrophages via Fc and complement receptors. Internalisation and killing can then occur. Thus the defect in someg patients with SLE could relate to a defect in opsonisation, Fc receptor function, or tissue macrophages.

There have been no studies evaluating the abilit of sera from patients with SLE to opsonise encapsu? lated bacteria. One recent report found a decrease $\$$ ability of sera from patients with SLE to opsonis $\overrightarrow{5}$ other bacteria, including certain strains of staphylo $\Xi$ cocci, owing to interference by circulating immune complexes. ${ }^{9}$ The possibility that circulating immune. complexes interfere with the ability to opsonisev encapsulated bacteria has not been similarly investio gated. The role of hypocomplementaemia in this patient's clinical course is unclear as we do not know the complement levels before the development of bacteraemia, and thus the contributions of her bacteraemia and SLE in inducing hypocomplem? entaemia cannot be discerned.

A defect in $\mathrm{Fc}$ receptor function and the reticu loendothelial system has been recorded in somes patients with SLE. A few patients had irreversible defects with splenic atrophy and marked lymphocyte depletion found at necropsy. ${ }^{10}$ In others the defect has been at least partially reversible and correlate $\mathbb{E}$ best with disease activity and titre of circulating immune complexes. ${ }^{11}$ This led early investigators to suggest circulating immune complexes were saturat $-\rightarrow$ ing Fc receptors, thereby blocking attachment and clearance of opsonised antigens. According to this theory the number of available Fc receptors on the? surface of mononuclear phagocytes in patients with SLE should be reduced. Fries et al, howevero showed a $40 \%$ increase in the number of availables 
Fc receptors on the cell surface of blood monocytes of patients with SLE. ${ }^{12}$ This finding suggested a primary defect in $\mathrm{Fc}$ receptor function in SLE and not an acquired blockade by circulating immune complexes. In fact this defect may allow both opsonised particles and circulating immune complexes to accumulate in the circulation. This may explain the increased risk of infection and the ability of immune complexes to be deposited in various tissues, causing the diverse clinical manifestations of SLE.

Further investigation has shed some light on the conflicting reports of decreased $\mathrm{Fc}$ receptor function associated with increased Fc receptor number. Salmon et al demonstrated significantly decreased $\mathrm{Fc}$ receptor mediated internalisation of opsonised particles in patients with SLE despite increased Fc fragment-Fc receptor binding. ${ }^{13}$ Although the extent to which this internalisation defect is involved in SLE remains unknown, it may explain several aspects of disease activity and the intrinsic increased risk of severe infections by encapsulated organisms.

Owing to our patient's rapid demise, it was impossible to delineate a specific defect in the reticuloendothelial system or the Fc receptor. The marked degree of bacteraemia (organisms seen on the peripheral blood smear) and increased circulating immune complexes, however, point to a defect in the immunological clearance pathway. As previously mentioned there are few data to support an opsonisation defect, and at necropsy the spleen showed no significant atrophic changes, suggesting our patient's dysfunction may have been at the level of the $\mathrm{Fc}$ receptor. We therefore present this case as a possible clinical correlate to the in vitro studies documenting a defect in the Fc receptor. This case highlights the increased risk of overwhelming pneumococcal infection in some patients with SLE. If the defect is at the level of the Fc receptor the use of the pneumococcal vaccine may be of little or no help in preventing this often fatal complication.

\section{References}

1 Nived O, Sturfelt G, Wollheim F. Systemic lupus erythematosus and infection: a controlled and prospective study including an epidemiologic group. $Q \mathrm{~J}$ Med 1985; 218: 271-87.

2 Urowitz M, Bookman A, Koehler B, et al. The bimodal mortality of systemic lupus erythematosus. Am J Med 1976; 60: 221-5.

3 Ginzler E, Diamond H, Kaplan D, Weiner M, Schlesinger M, Seleznick M. Computer analysis of factors influencing frequency of infection in systemic lupus erythematosus. Arthritis Rheum 1978; 21: 37-44.

4 Staples P, Gerding D, Decker J, Gordon R. Incidence of infection in systemic lupus erythematosus. Arthritis Rheum 1974; 17: 1-10.

5 Bisno A, Freeman J. The syndrome of asplenia, pneumococcal sepsis, and disseminated intravascular coagulation. Ann Intern Med 1970; 72: 389-93.

6 Hatch J, Sibbald W, Austin T. Overwhelming pneumococcal infection in a hyposplenic adult. Can Med Assoc J 1983; 129: 851-4.

7 Abramson S, Kramer S, Radin A, Holzman R. Salmonella bacteremia in systemic lupus erythematosus. Arthritis Rheum 1985; 28: 75-9.

8 Klippel J H, Karsh J, Stahl N I, Decker J L, Steinberg A D, Schiffman G. A controlled study of pneumococcal polysaccharide vaccine in systemic lupus erythematosus. Arthritis Rheum 1979; 22: 1321-5.

9 Nived O, Linder C, Odeberg H, Svensson B. Reduced opsonisation of protein A containing Staphylococcus aureus in sera with cryoglobulins from patients with active systemic lupus erythematosus. Ann Rheum Dis 1985; 44: 252-9.

10 Dillon A, Stein H, English R. Splenic atrophy in systemic lupus erythematosus. Ann Intern Med 1982; 96: 40-3.

11 Lockwood C M, Worlledge S, Nicholas A, Cotton C, Peters D K. Reversal of impaired splenic function in patients with nephritis or vasculitis (or both) by plasma exchange. $N$ Engl J Med 1979; 300: 524-30.

12 Fries L F, Mullins W W, Cho K R, Plotz P H, Frank M M. Monocyte receptors for the Fc portion of IgG are increased in systemic lupus erythematosus. J Immunol 1984; 132: 695-700.

13 Salmon J E, Kimberly R P, Gibofsky A, Fotino M. Defective mononuclear phagocyte function in systemic lupus erythematosus: dissociation of $\mathrm{Fc}$ receptor-ligand binding and internalization. J Immunol 1984; 133: 2525-31. 